\title{
Democratic Republic of Timor-Leste: Poverty Reduction Strategy Paper- Joint Staff Advisory Note
}

The attached Joint Staff Advisory Note (JSAN) on the Poverty Reduction Strategy Paper for the Democratic Republic of Timor-Leste, prepared by the staffs of both the World Bank and IMF, was submitted with the member country's Poverty Reduction Strategy Paper (PRSP) or Interim PRSP (IPRSP) to the Executive Boards of the two institutions. A JSAN evaluates the strengths and weaknesses of a country's poverty reduction objectives and strategies, and considers whether the PRSP or IPRSP provides a sound basis for concessional assistance from the Bank and Fund, as well as for debt relief under the Enhanced Heavily Indebted Poor Countries (HIPC) Debt Initiative. The Boards then decide whether the poverty reduction strategy merits such support.

To assist the IMF in evaluating the publication policy, reader comments are invited and may be sent by e-mail to publicationpolicy@imf.org.

Copies of this report are available to the public from

International Monetary Fund • Publication Services

$70019^{\text {th }}$ Street, N.W. $\bullet$ Washington, D.C. 20431

Telephone: (202) 623-7430 • Telefax: (202) 623-7201

E-mail: publications@imf.org • Internet: http://www.imf.org

Price: $\$ 15.00$ a copy

\section{International Monetary Fund Washington, D.C.}





\section{INTERNATIONAL MONETARY FUND AND \\ INTERNATIONAL DEVELOPMENT ASSOCIATION}

DEMOCRATIC REPUBLIC OF TIMOR-LESTE

\section{Joint Staff Advisory Note on the Poverty Reduction Strategy Paper}

Prepared by the Staffs of the International Development Association and the International Monetary Fund

Approved by Jemal-ud-din Kassum (IDA) and, Daniel Citrin and Carlo Cottarelli (IMF)

April 29, 2005

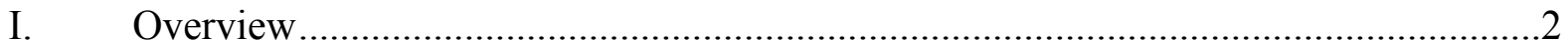

II. The National Development Plan ..........................................................................4

A. NDP Design and Implementation .........................................................

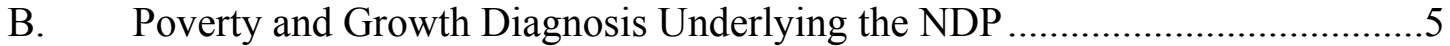

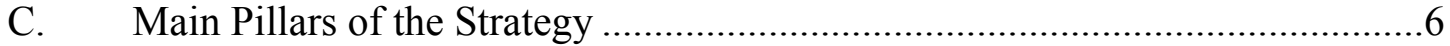

III. Implementation Challenges ………………......................................................

A. Encouraging Macro-Economic Stability and Growth through the Effective Use of Oil and Gas Wealth ...................................................................................

B. Building Institutional Capacity for Service Delivery and Providing Quality

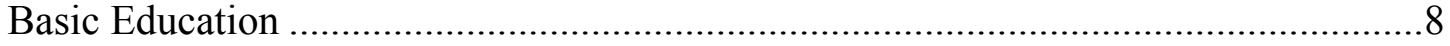

C. Strengthening Governance, Especially the Justice Sector and Customs .........10

D. Supporting Job Creation by Improving the Investment Climate ......................11

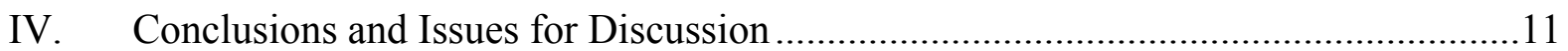




\section{OVERVIEW}

1. The authorities are presenting the Democratic Republic of Timor-Leste's National Development Plan 2002 (NDP) and associated implementation documents to the Boards in order to indicate the progress achieved by the country during the past three years. This Joint Staff Advisory Note (JSAN) has four sections: Section I provides an overview. Section II outlines key elements in NDP design and implementation. Section III identifies key challenges faced in NDP implementation and provides suggestions for both strengthening the strategy and addressing implementation risks. Section IV concludes and proposes issues for discussion by the Boards.

2. In 1999, the citizens of Timor-Leste voted for independence in an UN-managed referendum. The country was under UN administration until May 2002, when the first Government assumed power. It was during this period that the National Development Plan (NDP) was developed. Since then, the government has produced a Road Map and Stability Program for NDP implementation in 2003, and developed Sector Investment Plans (SIPs) to further guide this process in 2004.

3. The NDP presents Timor-Leste's long-term development vision and its development strategy for the period 2002-2007, which coincides with the mandate of the country's first elected Government. Preparation began in September 2001, under the direction of the Second Transitional Government. A program of nation-wide consultations was launched in early 2002, culminating in a series of national workshops. The NDP was approved by Parliament at Independence in May 2002 and the key messages were disseminated to all households and schools in a booklet entitled "East Timor 2020: Our Nation, Our Future." The NDP builds on the results of poverty diagnosis and a participatory planning process, laying out a poverty reduction strategy which recognizes the multiple dimensions of poverty. The poverty reduction strategy is translated into development goals, guiding principles, outlines of sector strategies and a macro-economic and medium-term expenditure framework for the first five years after independence. The NDP is a living plan which has guided policy development and implementation since 2002.

4. In 2003 and in the aftermath of riots in December 2002 related to slow progress on poverty reduction, the government produced a Road Map to NDP implementation and an associated Stability Program which identify "priorities of priorities" within the NDP. These documents focus on the areas considered essential to preserve economic and social stability, elaborate on prioritization and sequencing issues, and provide a costed implementation program for each ministry for the period 2003-2007.

5. The development of seventeen SIPs and an accompanying medium-term expenditure framework has further facilitated NDP implementation. During 2004, the government completed preparation of SIPs as well as two umbrella reports which provide the overall framework for the individual papers and outline a process for moving forward with implementation. The seventeen SIPs build on sector strategies to provide costed sector 
programs within a consistent macro-economic framework. Agency-level annual action plans (AAPs) linked to budgets provide the basis for policy implementation on a yearly basis.

\section{The NDP and subsequent implementing documents have also provided the} framework for coordination of external assistance. By articulating the Government's priorities and strategy, these documents have guided the realignment of external assistance from reconstruction to development. They have also served as an operational tool, helping external partners identify priorities and programs where they have a comparative advantage and minimizing the duplication and overlap often seen in small, post-conflict countries. The continued support and coordination of the donor community will be needed if the government's ongoing effort to ensure the alignment of external assistance with national priorities is to be achieved.

7. Since its independence, Timor-Leste has made progress in NDP implementation by maintaining peace and stability, building state institutions and improving service delivery. The country has made strides in healing past divisions and building the political unity necessary for nation-building. Key state organs including the Executive, Parliament, Judiciary, and the Office of the President have been endowed with policy and legislative frameworks, human and financial resources and physical infrastructure. There has also been progress in the area of service delivery. Many health facilities across the country have been rehabilitated, immunization and birth attendance rates have increased and infant and child mortality have declined. Schools have been rehabilitated, teachers are in place and primary school enrolment rates have increased nationwide. Roads and water supply systems have been rehabilitated in parts of the country and more reliable energy supply has been restored to Dili since the rehabilitation of its power station and the institution of a cost recovery system. In the agriculture sector, production of rice has recovered owing to the rehabilitation of irrigation systems while livestock health services have been restored.

8. While there has been progress in implementation, significant challenges remain. Key constraints to achieving sustainable growth, poverty-reduction and improved governance in Timor-Leste include: weak capacity, reflecting its embryonic institutions and limited human resources; a stagnant economy, with high levels of poverty and unemployment; unrealistic expectations about what can be achieved in the short term; and the challenge of managing oil/gas resources soundly in this difficult environment. Therefore, the remainder of the document will discuss the principal challenges ahead and the priority measures needed to address them. The Bank and Fund staffs believe these principal challenges are: i) encouraging macro-economic stability and growth through the effective use of oil and gas wealth; ii) building institutional capacity for service delivery and providing quality basic education; iii) strengthening governance and the judiciary; and iv) supporting job creation by improving the investment climate. 


\section{The National DeVelopment Plan}

\section{A. NDP Design and Implementation}

9. The NDP was prepared through a broad-based government-led consultative process. Plan preparation was coordinated by cross-sectoral working-groups, led by Ministers. Technical work was informed by a participatory poverty assessment, followed by country-wide consultations which solicited input from over 38,000 people in 980 public meetings. The NDP was discussed at a two-day workshop with a broad set of stakeholders, including civil society, the Catholic Church, and development partners. The workshop results were incorporated into the final version of the NDP, which was approved by Parliament at independence.

10. The NDP sets out the country's vision for development, its main objectives and targets, key sector policies and a medium-term macro-fiscal framework but, like most PRSPs, it does not include a costing of the sector strategies needed to implement the plan. The elaboration and costing of sector strategies and their integration into a mediumterm fiscal framework has advanced through the development of the Road Map, SIPs and medium-term expenditure framework. This planning and budgeting process was outlined in the NDP, but has mainly emerged during its implementation phase.

11. Since 2002, the Government has put in place annual planning routines as part of the budget process, and the staffs recommend that further work be done to link plans, budgets, outputs and performance. Each ministry prepares an Annual Action Plan (AAP) to inform budget preparation. Progress in implementation is monitored through Quarterly Reporting Matrixes (QRMs). Most AAPs and QRMs provide considerable detail on the activities planned and undertaken at departmental level, but little information on the quantity and quality of the services provided to the public. The Ministry of Health has made progress in establishing a performance monitoring framework linked to key service delivery indicators. The staffs encourage the government to extend this practice to other service delivery sectors. Ultimately, a few key performance indicators for each program should be presented in the budget documents, thereby linking resource allocations to the services provided and program level performance. In the meantime, the contribution of QRMs to the monitoring process could be fostered by strengthening their analytical component and using their information as an input into the budgeting process.

\section{The Sector Investment Programs (SIPs) provide an opportunity to align} resource allocations with NDP and sector priorities, and the staffs recommend that they be prepared on a rolling basis. Preparation of the SIPs on a rolling basis would provide the basis for strengthening medium-term budgeting and improving the alignment between sector strategies, plans, budgets and external assistance. It would also support the government's ongoing efforts to develop a Combined Sources Budget that covers its own resources as well as those of development partners. 
13. The recent establishment of joint government-donor Sector Working Groups (SWGs) to support SIP implementation and monitoring is a very positive development, and the staffs recommend extending their membership to civil society organizations. The staffs commend the Government's initiative in establishing SWGs in agriculture, infrastructure, and health and encourage the establishment of the remaining groups. The staffs also recommend that the groups' sector monitoring function be fully exploited and encourage the Government to extend their membership to civil society organizations as originally envisaged in the NDP. The SWGs provide an avenue to institutionalize the participatory process initiated with the development of the NDP and the staffs encourage the Government to make full use of this opportunity.

14. The staffs encourage the government to complete the monitoring and evaluation framework envisaged in the NDP by assigning responsibility for this function to a specific unit and charging it with tracking a small number of core NDP indicators. The role of this central unit, the Office of National Statistics and line ministries should be clearly defined and coordination mechanisms clearly spelled out. This unit should lead the upcoming NDP assessment exercise and devise mechanisms to foster feedback loops into policymaking.

\section{B. Poverty and Growth Diagnosis Underlying the NDP}

15. The NDP drew on a Poverty Assessment (2001) that provides a detailed picture of the nature and extent of poverty in Timor-Leste. The report reviews the main determinants of poverty and assesses its regional and gender dimensions. The results of this assessment are presented in the "State of the Nation Report" of April 2002, which provides the analytical basis for the policy options presented in the Plan. In addition, since 2002, there has been an extensive program of survey work which provides a potentially rich resource for poverty and policy analysis. A Multiple-Indicator Cluster Survey was undertaken in 2002, a Demographic and Health Survey in 2003 and the first Population Census in 2004, while a second round of the living standards survey is tentatively scheduled to begin field operations in January 2006.

16. Based on this and subsequent assessments, Timor-Leste is among the poorest countries in the world. The GDP per capita is US\$ 405, one in five people lives on less than one dollar per day and two in five live below the national poverty line. Inequality is also high, with the poorest 40 percent of the population having an expenditure share of less than 18 percent. Two out of five adults are illiterate, half of children under five are stunted and the under-five mortality rate is 83 deaths per 1,000 live births. In urban areas, around 70 percent of the population has access to electricity and safe drinking water, but in rural areas, access rates are only 43 percent for drinking water and 11 percent for electrification. Moreover, high fertility and population growth rates compound the challenges of improving the welfare of the poor in Timor-Leste.

17. The poverty reduction goals and targets set in the NDP are aligned with the MDGs but are often over-ambitious and could usefully be revisited. Achievement of 
some of the targets set is unlikely to happen over the plan period. For instance, while no new survey data are available to conclusively verify this, with the estimated decline in non-oil per capita income since 2002, the incidence of poverty is likely to have increased. Similarly, in the health and education sectors, improvements are likely but the achievement of the ambitious targets set in the NDP remain unlikely. Therefore, there is a case for a review of poverty reduction goals as part of the upcoming NDP assessment as well as a need to further specify targets in quantitative (and not just directional) terms.

18. The medium-term macro-economic objectives included in the NDP remain broadly valid, but the recent large increases in international oil prices and the acceleration of the oil production schedule present new opportunities and challenges. As envisaged in the NDP, following independence, non-oil economic activity decelerated in response to the end of the emergency reconstruction phase and the related reduction in international presence. The economy recovered only modestly in 2004, as a rebound in agriculture following a drought offset a further drawdown in the UN presence. Supported by the dollarized monetary regime and cautious macroeconomic policies, inflation declined to below 3 percent. The start of oil revenue inflows combined with high oil prices led to a sharp narrowing of the external current account deficit in 2004, while a sizable fiscal surplus of about 70 percent of non-oil GDP is expected for the current fiscal year. However, the development of non-oil private economic activity has not yet started and the execution of budgetary public investment has been low because of limited capacity.

\section{Although the initial effort in poverty diagnostics has been strong, staffs} encourage deepening understanding of the determinants of growth and poverty patterns in Timor-Leste. While these initial diagnostics provide a snapshot of the current situation, the elaboration of poverty trends will require institutionalizing the surveying effort. The challenge in this regard will be to maintain donor support and participation by a small population which may increasingly suffer from 'survey fatigue." Development of domestic capacity for poverty analysis, fostering feedback loops into policy-making and strengthening dissemination efforts will also be critical to ensuring poverty diagnostics have the desired impact.

\section{Main Pillars of the Strategy}

20. The NDP identifies sustainable growth and poverty reduction as its overriding goals. Sustained economic growth is seen as a precondition for poverty reduction, with citizens and the private sector as the driving force and the government as the facilitator including through the execution of a well focused public investment program aimed at basic service delivery and the establishment of essential infrastructure. To ensure that growth has a significant impact on poverty reduction, the NDP proposes a poverty reduction strategy with four pillars: creation of opportunities for economic participation; delivery of basic social services; provision of security of person and property, and protection against unforeseen shocks; and empowerment of citizens and communities.

21. Within this broad framework, the Road Map and Stability Program focus on three areas of the longer-term program where the government intends to have an 
immediate impact: governance, service delivery for poverty reduction, and job creation. Good governance encompasses strengthening the administrative structures of the state, the justice system and the security forces. Service delivery is aimed at reducing poverty by supporting education, health, food security and enhanced access to markets for rural producers. Job creation centers on maintaining stability by supporting agriculture and private sector development and emphasizing youth and veterans of the resistance.

\section{IMPLEMENTATION CHALLENGES}

\section{A. Encouraging Macro-Economic Stability and Growth through the Effective Use of Oil and Gas Wealth}

22. The NDP and more recently the SIPs acknowledge that to reach the country's ambitious growth targets and poverty-reduction objectives strong commitment to prudent macroeconomic policies and the continuation of donor support are needed. The authorities have preserved their commitment to the dollar currency regime, which has been critical to maintaining low inflation, together with a prudent fiscal policy. In addition, the absence of external and domestic debt provides the government with a degree of freedom in economic management unavailable to most low-income countries. At the same time, the targeted medium-term non-oil growth of 6 percent that is needed to absorb a rapidly increasing labor supply is not likely to be achieved without more effective efforts in two areas. First, an adequate environment needs to be created for the development of private sector non-oil activity, including in the rural regions. Second, difficulties in budget execution constraining development spending, particularly infrastructure expenditure, for more rapid economic growth and poverty alleviation need to be addressed. At the same time, financing of the central government budget will not pose difficulties as annual fiscal surpluses of 34-40 percent of non-oil GDP are expected over the medium-term, based on most recent oil price projections. Despite these surpluses, Timor-Leste will need the continued support of the donor community for some years to come to assist in the design and execution of development projects for which domestic capacity is not yet available.

23. The onset of substantial oil/gas production from Bayu Undan in 2004 and much higher international oil prices than envisaged in the NDP create new opportunities, while raising new challenges for the government. Recent estimates of revenue for Timor Leste from currently assessed oil and gas reserves in Bayu Undan range between US\$ 2 to 5 billion over the 20 years production life of the field, on the basis of oil prices in the range of US\$25 to 45 per barrel. These large oil/gas revenue inflows provide much-needed financial resources, but also present the challenge of managing transparently and effectively large and volatile oil/gas revenue for current and future generations of Timorese. In addition, the large revenue inflows further emphasize the need to place a high priority on establishing a supportive environment for private sector activity in order to avoid adverse effects on the non-oil economy.

24. Timor-Leste has made significant progress in designing a system to handle its new oil/gas wealth responsibly and the staffs commend the government on its plans to 
proceed with implementation in the year ahead. Oil/gas taxation has been streamlined, the draft Petroleum Fund Act to establish a Norwegian-style petroleum fund-based on high standards of transparency and accountability-has been submitted to Parliament and is expected to be operational by July 2005, and a long-term savings policy has been adopted. The new sustainable income fiscal policy sets annual budget spending equal to the sum of domestic non-oil revenue and the estimated permanent annual income from the oil wealth. With the creation of the petroleum fund and adherence to the new savings policy, Timor Leste will have established the long-term fiscal strategy needed to ensure productive and transparent use of oil/gas wealth while safeguarding fiscal stability. Nonetheless, risks at the implementation stage are possible, given limited administrative and financial management capacity. Should the establishment of the fund be delayed, the already large revenue inflows underscore the need to follow the fund's basic principles of transparency and accountability. The staffs also look forward to the establishment of the investment advisory board, the petroleum fund consultative council, and a framework for regular reporting to the public in time to support the launch of the petroleum fund.

25. Against the background of the better-than-expected outlook for fiscal revenue, a significant increase in total expenditure is targeted for the medium-term. Given the considerable development needs in Timor Leste, the staffs support moving toward the sustainable spending level (estimated at about \$130 million annually) as quickly as administrative and absorptive capacity in the economy would allow without aggravating either nonpriority spending levels or inflationary pressures. Nonetheless, the rapid overall proposed spending increases appear ambitious, barring a sharp improvement in spending capacity. Increases in this range also raise the risk of less well prioritized spending and of triggering inflationary pressures, given still limited absorptive capacity in the domestic economy. Therefore a more gradual but steady movement toward reaching the sustainable spending level would be advisable.

\section{B. Building Institutional Capacity for Service Delivery and Providing Quality Basic Education}

26. Improving the availability, efficiency, and quality of public services will be essential to delivering tangible results to the population. Ensuring affordable access to quality services in education, health, agriculture, and infrastructure in the context of a rapidly growing and dispersed population, however, will be a major challenge. The challenge will not initially be one of resource availability but rather of government capacity to manage resources available to effectively deliver the desired services.

27. Enhanced service delivery will require, in the long run, enhanced institutional capacity and, in the short run, the establishment of partnerships. Current capacity is weak and vulnerable to the departure of a large number of international advisers. Over the next few years, strengthening government capacity to design, manage, implement and monitor its policies and budgets will be the central challenge. Over the short run, however, much could be done to improve budget execution while enhancing service delivery to the population. Therefore, the staffs encourage the government to consider possibilities that 
would allow for effective service delivery in the short-run while building up sustainable government capacity in the medium-term. In this regard, the government may wish to consider establishing creative partnerships with civil society, the church and the private sector while state capacity is strengthened. Elaborating and implementing capacity-building strategies for key government ministries, possibly in conjunction with development partners, would also be an important building block to improving institutional capacity for service delivery.

28. Public finance management poses a particular challenge to service delivery as budget execution capacity is extremely limited and the staffs encourage the government to streamline public finance management systems. A combination of complex and overcentralized processes, and weak human resource and institutional capacity on the one hand, and a high level of commitment to fiduciary accountability on the other, results in very low levels of budget execution. As a result, a high percentage of budgeted resources remain unspent with implications for service delivery. In this regard, strengthening the Government's institutional capacity will require increased individual skills and knowledge, improved systems and processes and supportive attitudes and behaviors. In particular, the Government should consider filling existing vacancies, preparing succession plans for the departure of international advisers and increasing delegation of public expenditure management functions within ministries and elaborating plans for decentralization to line ministries and districts. Moreover, enhanced coordination between line ministries, the Ministry of State Administration and the Ministry of Planning and Finance would be an important contribution to improving public finance management and service delivery. At the same time, the commitment to fiduciary accountability should be maintained even as the reforms to improve budget execution are undertaken. The support of the donor community to develop a comprehensive program for strengthening public finance management will be critical to address this bottleneck to NDP implementation.

29. An educated population will be the best asset to support economic growth and good governance in Timor-Leste. Although some progress has been made over the past three years, Timor-Leste's literacy rate is only 60 percent and the sector faces enormous challenges. Considerable progress has been made since the destruction of 1999 in the physical reconstruction of schools and in teacher deployment and student enrollment rates have expanded. Moreover, a National Education Policy, a Basic Education Law and the framework for the primary education curriculum have been drafted. The key challenge ahead will lie in further increasing enrollment rates while reducing currently high drop-out and repetition rates. These improvements will require the adoption and implementation of a medium to long-term program to improve access to and quality of basic education. To achieve this, the Ministry has set a target of universal primary school completion by 2015 and is developing an Education for All (EFA) strategy that will direct the majority of government and donor resources for the sector to primary education. Key to the success of the EFA program will be improved donor coordination in the sector as well as enhanced Government capacity to develop, implement and monitor its policies and budgets. The Government may also wish to consider revising its policy on primary education user fees, 
which weigh heavily on the poor while a high percentage of the education sector budget goes unspent.

\section{Strengthening Governance, Especially the Justice Sector and Customs}

30. In the area of governance, the architecture of checks and balances set out in the Constitution remains to be completed and strengthened and decisive action will be needed to combat corruption. Strengthening governance will require the reinforcement of non-executive state institutions such as the Parliament, the judiciary, the Provedor dos Direitos Humanos e da Justiça, and the Consultative Council that will be established to oversee the management of the Petroleum Fund. Good governance also depends on independent audit and the development of professionalism and a spirit of public service within Government agencies.

31. In the year ahead, priority attention should be devoted to the justice sector and customs administration. All acting Timorese judges have failed their qualifying test and will need to be replaced while they undergo training. Therefore, the planned elaboration of a medium-term human resource development plan covering both the recruitment of international and the training of Timorese court actors will be of the utmost importance. Developing a resource mobilization strategy to support this plan before the withdrawal of UNMISET, which currently funds and recruits international court actors, will also be necessary. Finally, the design of a case management system and, more broadly, sounds systems and processes will also be needed to improve the performance of the sector.

32. Customs has registered significant improvements and the staffs encourage the government to proceed with the second stage of their reform program. Over the past year, the collection of import duties has increased, the value of Customs exemptions and the time required for Customs clearance have been significantly reduced and the effectiveness and integrity of staff have increased. These improvements are largely due to new leadership in Customs, the introduction of ASYCUDA (automated system of customs data administration) and accompanying reforms. In a second stage to begin this year, further reforms are envisaged under the ASYCUDA program, including the installation of a management information system, computerized risk assessment system and cargo manifest, the institutional strengthening of the Customs service, the extension of the new systems and reforms to the rest of the country (outside Dili), and a thorough training in systems and ethics.

33. Transparency and communications and fostering external scrutiny will be critical to the achievement of these goals. Transparency and communications with regard to public activities, oil revenues, expenditures, and financial management are particularly critical assets for good governance in an environment of still-fledgling institutions. In particular, the staffs commend the Government on its commitment to publish detailed accounts of all revenues received by the petroleum fund and encourage the publication of budgets and executed budget figures. Moreover, the development of external scrutiny will be essential to balancing out a strengthening state. This development should be encouraged by 
creating the enabling environment for a healthy and dynamic civil society, private sector and media. Finally, much of the progress made in Timor-Leste over the past three years has centered on developing the policy framework and establishing state institutions. While positive and necessary, these gains are largely invisible to the population. Therefore, effective communication and genuine participation are critical to shoring up popular support for the national development process while service delivery capacity is strengthened.

\section{Supporting Job Creation by Improving the Investment Climate}

34. Job creation in the private sector will be critical for the achievement of poverty reduction goals and maintaining economic and political stability in the long run. Over half the population is under 15 , a percentage which will continue to increase due to a population growth rate of over 3 percent per annum. This large and growing group of young people will continue to enter the labor market each year requiring significant growth in job creation. Moreover, lack of economic opportunities in rural areas is leading to high levels of migration to urban centers. Urban youth unemployment was 43\% in 2001, and has probably increased since. Therefore, growth in labor-intensive agriculture and agro-industry in rural areas will be essential to reducing poverty and inequality throughout the country. Poor performance in this area could lead to mounting pressure for Government to relax its savings policy and fiscal discipline and expand the size of the public sector. It could also undermine social and political stability.

35. Job creation, however, remains a major challenge and the staffs encourage the government to enact measures to improve the legislative and regulatory environment for businesses. Timor-Leste suffers from a combination of relatively high wages and energy prices, poor communications, high administrative costs of doing business and legislative and regulatory uncertainty. Improvements in infrastructure will be critical to lowering the costs of doing business as well as enhancing market access for the rural population. The role of government institutions will also be key to improving the investment climate, as will be intensive dialogue between government and the private sector. Providing the necessary political and budgetary support to the recently-established Investment and Export Promotion Agency will be important, as will be the continuation of dialogue with the private sector. In this regard, the first national-level Business-Government Dialogue forum, scheduled for midApril 2005, is expected to focus on reducing the costs of and the regulatory burden on doing business and the staffs encourage the government to carefully consider and act upon the recommendations emerging from this forum.

\section{CONCLUSIONS AND ISSUES FOR DISCUSSION}

36. The NDP and subsequent strategy and policy documents provide a sound framework for poverty-reduction while the institutional and regulatory framework for the management of oil and gas resources constitutes best practice. The government has also made progress in the planning, budgeting and reporting areas and has a high level of fiduciary accountability, in particular for a low-income country. 
37. Implementation, however, remains a challenge. The poverty situation in TimorLeste is extremely challenging while administrative capacity is low. To support the government in addressing these challenges, the staffs have identified five priority areas for effective NDP implementation. These areas are: (i) building institutional capacity for effective service delivery; ii) encouraging more rapid economic growth by effectively managing oil and gas resources and ensuring macroeconomic stability; (iii) strengthening governance; iv) providing high-quality basic education; and v) establishing an enabling environment for private sector activity to enhance job creation.

38. It is proposed that the document produced for discussion at the annual TimorLeste Development Partners meeting be used for PRS reporting purposes. This document outlines progress in the previous year and sets out the main policy and budget guidelines for the year ahead. The proposed route to reporting would have the twin advantages of supporting the ongoing improvement of the quality of existing reporting documents while not burdening the government with additional reporting requirements.

39. Do the Executive Directors concur with: (i) the broad direction of the proposed strategy as outlined in the NDP; (ii) staffs' characterization of implementation challenges; and (iii) staff's recommendations for strengthening the implementation, monitoring and evaluation of the NDP. 